\title{
Discurso, mídia e produção de sentidos: questões de leitura e de formação na contemporaneidade
}

Maria da Glória Corrêa di Fanti*

\section{Resumo}

Considerando a diversidade de discursos que circulam na mídia e a necessidade de se comprender os diferentes funcionamentos de construção de sentidos, trazemos para discussão duas charges que ilustram a problemática relativa à leitura na contemporaneidade. A primeira charge, publicada em 30 de dezembro de 2011, ao gerar variadas reações de leitores, provocou o surgimento de uma segunda charge, em 05 de janeiro de 2012. Este artigo, visando apresentar reflexões sobre como os sentidos são produzidos nas charges selecionadas, busca ilustrar de que maneira a teoria bakhtiniana, que subsidia teoricamente esta reflexão, pode contribuir para a análise de gêneros midiáticos mais ou menos complexos e, consequentemente, colaborar para a formação de leitores proficientes.

Palavras-chave: Leitura. Charge. Produção de sentidos. Tensão. Teoria dialógica do discurso.

\section{Considerações iniciais}

Parece inquestionável que vivemos em uma sociedade de informação, já que na atualidade, em especial nos centros urbanos, se tem acesso a uma grande quantidade de materiais disponíveis. Assim como há espaços seletivos reservados para leitura, arte e educação, como bibliotecas, livrarias, cinemas, teatros, universidades, escolas, etc., há também, com uma abrangência bem maior, espaços em que circulam outras formas de informação, arquitetadas em diferentes linguagens verbais e não verbais, via televisão (noticiários, programas de auditório, reportagens, novelas, entrevistas, documentários, anúncios publicitários, etc.), internet (sites, redes sociais, e-mail, etc.), espaço público (outdoors, panfletos, etc.), revistas, jornais, entre outros.

\footnotetext{
Docente do Programa de Pós-Graduação em Letras da Pontifícia Universidade Católica do Rio Grande do Sul. Desenvolve pesquisa com o apoio da Fapergs (Edital Pesquisador Gaúcho - 2014). E-mail: gloria.difanti@ pucrs.br
}

Data de submissão: set. 2015 - Data de aceite: nov. 2015

http://dx.doi.org/10.5335/rdes.v11i2.5503 
Se, por um lado, há muitos meios de se ter acesso à informação, por outro, há um problema que afeta a sociedade contemporânea: a inconsistência da formação. O que se observa é que informação e formação não caminham necessariamente na mesma direção. Nesse cenário, nós, profissionais da área da linguagem, que atuamos na graduação e pós-graduação, nos deparamos com desafios constantes no exercício da formação acadêmica. Será que, em meio a tanta informação, estamos formando pesquisadores e leitores críticos, capazes de discernir, fazer escolhas e compreender ativamente os discursos em circulação, tornando-se sujeitos de sua formação? Será que estamos formando pesquisadores e professores capazes de também formar leitores críticos em suas práticas tanto na Escola como na Universidade?

Partindo desses questionamentos, desenvolvemos, com base na perspectiva bakhtiniana, a pesquisa $A$ constitutiva e tensa relação com o discurso do outro: questões de pesquisa e de formação na contemporaneidade (DI FANTI, 2014), voltada para o estudo da tensão entre discursos, como dimensão fundamental da constituição do discurso e da construção dos sentidos. ${ }^{1} \mathrm{O}$ que se nota é que a relação de tensão é pouco desenvolvida tanto no que se refere à pesquisa, quanto ao ensino de leitura e produção de textos. Não é raro nos depararmos com pesquisas embasadas na teoria bakhtiniana que tratam da relação entre discursos, o que é pouco contemplado, no entanto, é como podemos perceber a constitutiva relação de tensão entre os discursos. No que se refere ao ensino, da mesma forma, não reparamos essa preocupação. É comum, por exemplo, trabalhar-se com noções como gêneros do discurso, central para o ensino, mas deixar de lado a tensão, ou seja, o conflito constitutivo da produção de linguagem, da produção dos sentidos, como é o caso da relação entre aspectos estáveis e instáveis, elementos repetíveis e irrepetíveis do gênero. A questão das escolhas do locutor, observadas a partir do projeto enunciativo e pelos recursos de linguagem, ao mobilizar um determinado gênero se, por um lado, entram em relação de aproximação com alguns discursos, por outro, entram em relação de distanciamento.

Nesse caminho, considerando a diversidade de gêneros em circulação, temos nos debruçado sobre a análise de discursos midiáticos, de modo a desenvolver reflexões que proporcionem compreender como os sentidos se produzem na e pela linguagem, bem como se criam efeitos outros de sentido que podem não ser percebidos por leituras superficiais. Os discursos da mídia são férteis para essa reflexão devido aos variados funcionamentos e também à força midiática em fazer circular uns e não outros discursos, conforme o público que quer atingir. Ademais, como entende Charaudeau (2009, p. 19), a mídia, dentre seus apelos, para atingir um maior número de interlocutores, constrói discursos a partir de uma "hipótese fraca", ao considerar 
seus interlocutores pouco esclarecidos. A "hipótese forte" exigiria maior esclarecimento por parte dos interlocutores, o que reduziria a abrangência midiática. Tais considerações permitem observar a importância do grau de esclarecimento por parte do público-alvo da instância midiática, que poderá ser mais ou menos crítico frente à opacidade própria da linguagem e seus recursos verbais e não verbais.

Considerando o cenário apresentado, trazemos para reflexão duas charges de autoria do cartunista Iotti, uma publicada no dia 30 de dezembro de 2011 e a outra no dia 05 de janeiro de 2012 no jornal Zero Hora. A primeira charge, apresentando uma arquitetônica mais complexa comparada à segunda, ilustra a problemática relativa à dificuldade de leitura, no que tange à necessidade de formar leitores proficientes que compreendam o funcionamento do discurso e os sentidos que são produzidos. A segunda charge emerge como uma resposta à primeira, em uma arquitetônica acessível para diferentes leitores, tentando mostrar para o público que não entendeu a primeira charge a posição do cartunista Iotti.

O objetivo deste artigo é apresentar reflexões sobre como os sentidos são produzidos, de modo a ilustrar de que maneira a teoria bakhtiniana pode contribuir para a análise de gêneros midiáticos mais ou menos complexos e, consequentemente, colaborar para a formação de leitores proficientes. No que tange à metodologia, tomando como pressuposto que há uma relação de tensão entre discursos e que é importante considerá-la nas práticas de leitura, são postos em discussão, em um primeiro momento, aspectos da constituição enunciativa do discurso da Charge 1. Em um segundo momento, é apresentada uma breve discussão sobre a Charge 2 , buscando desenvolver reflexões sobre as distintas arquitetônicas entre ambas e a consequente contribuição para a formação de leitor.

\section{Teoria dialógica do discurso: tensão entre discursos e construção de sentidos}

Desde os textos iniciais do Círculo de Bakhtin como é o caso de Para uma filosofia do ato (BAKHTIN, 19201924/2010), a questão da alteridade se apresenta como base para tratar do ato ético, responsável e responsivo, já que a relação eu / outro fundamenta a sua constituição. ${ }^{2} \mathrm{O}$ ato, entendido como um evento único do ser, é o meio para se superar toda forma de exclusividade, em especial a cultura e a vida, uma vez que só se pode observar uma dimensão a partir de outra. Assim, em sua inteireza, coexistindo diferenças, o ato, em sua irrepetibilidade, se constitui pela forma e o conteúdo, a teoria e a prática, o processo e o produto. Ao mesmo tempo, todo dado se realiza em conjunção com outros dados, dando origem a uma cria- 
ção única, com sentido singular. $O$ ato é de responsabilidade de um "eu", que não tem álibi para não o assumir, na indissociável relação com o "outro", instituindo a alteridade constitutiva.

Essa reflexão remete à tensa relação com o discurso do outro, que integra os fundamentos do pensamento bakhtiniano no que se refere à alteridade e ao dialogismo, observada em diferentes dimensões, como em eu-para-mim (como eu me vejo, tendo em vista a perspectiva do outro), outro-para-mim (como eu vejo o outro) e eu-para-outro (como o outro me vê) (BAKHTIN, 1922-1924/2003; 19201924/2010). Cada um, ocupando singularmente um lugar num tempo definido, pode ver no outro o que ele sozinho não consegue ver, pois são diferenciados horizontes de valor. Percebe-se assim uma relação de interdependência entre o eu e o outro, necessária para a constituição do sujeito, do discurso e do sentido. Tais facetas impõem a percepção de tensões, no dizer de Amorim (2007, p. 43), em que as diferenças não se fundem, "mas se multiplicam ao infinito". ${ }^{3}$

Procurando observar a relação de tensão nos conceitos do Círculo de Bakhtin a fim de iluminar as reflexões sobre a produção de sentidos a partir dos estudos da linguagem, notamos que todo discurso é parte integrante de uma discussão ideológica maior, ou seja, "responde a alguma coisa, refuta, confirma, antecipa as respostas e objeções potenciais, procura apoio etc." (BAKHTIN/VOLOCHINOV, 1929/1995, p. 123). Por mais completa que possa parecer, a enunciação "constitui apenas uma fração de uma corrente de comunicação verbal ininterrupta [...]", devendo, por isso, ser sempre explicada pelo seu vínculo com a situação concreta em um curso histórico. ${ }^{4}$

Em La construcción de la enunciación, Bajtin/Voloshinov destaca que:

[...] cada enunciação da vida cotidiana [...] compreende, além da parte verbal, uma parte extraverbal, subentendida - situação e auditório -, sem cuja compreensão não é possível entender a enunciação mesma (1929-1930/1993, p. 248).

Essa orientação social que pressupõe as projeções feitas ao outro tanto no que tange a aspectos verbais quanto a gestuais

[...] é uma das forças organizadoras vivas que, junto com a situação da enunciação, constituem não só a sua forma estilística, mas também sua estrutura gramatical (1929-1930/1993, p. 256).

Desse modo, a palavra e o gesto da mão, a expressão do rosto e a posição do corpo são igualmente dependentes da orientação social. Assim, a resposta ao interlocutor pode ser, se não com palavras, por gestos:

[...] um movimento de cabeça, um sorriso [...] etc. Pode-se dizer que qualquer comunicação verbal, qualquer interação verbal, se desenvolve na forma de intercâmbio de enunciações, ou seja, na forma de diálogo (1929-1930/1993, p. 250, grifo do autor, tradução livre).

Nessa perpectiva, toda enunciação, por mais monológica que possa parecer (palestra, discurso interior, etc.), é, em sua essência, dialógica, pois é impregna- 
da por valorações de outros discursos e sujeitos, como a de um ouvinte potencial.

Discorrendo sobre a constituição do enunciado, Bakhtin observa que, diferentemente da oração, unidade abstrata da língua, que não suscita atitude responsiva, o enunciado, unidade mínima da comunicação discursiva, é delimitado pela alternância de sujeitos responsivos que se valem do auxílio de formas linguísticas (BAKHTIN, 1952-1953/2003, p. 276). Desse modo, destaca que todo enunciado - desde uma única palavra até um romance de vários volumes tem "autor" e "destinatário" (BAKHTIN, 1952-1953/1992, p. 320-321). A percepção do "destinatário" ou a ideia que se tem dele "determina" a composição e o estilo do enunciado, a sua expressividade constitutiva. Em outros termos, o enunciado é tecido a partir de algumas questões: "A quem se dirige?"; "Como o locutor (ou o escritor) percebe e imagina seu destinatário?"; "Qual é a força da influência deste sobre o enunciado?". Com isso, como afirma o pensador russo, enquanto falamos, sempre levamos em conta quem é nosso interlocutor: "o grau de informação que ele tem da situação, seus conhecimentos especializados na área de determinada comunicação”.

O projeto enunciativo do dizer, articulado ao conjunto das projeções ao interlocutor, em uma situação específica, materializa-se em um dado gênero do discurso. Considerados como "tipos" de enunciados com relativa estabilidade, os gêneros são constituídos por estilo verbal (recursos linguísticos), forma composicional (estrutura) e tema (sentido singular) (BAKHTIN, 1952-1953/2003). Como formas discursivas dinâmicas, históricas e culturais, que permitem as interações verbais, os gêneros refletem de modo mais imediato, preciso e flexível as mudanças que transcorrem na vida social, uma vez que, inseparáveis das práticas sociais, se realizam em esferas de atividades humanas. Ainda que os gêneros discursivos apresentem características mais ou menos estáveis, são reelaborados, ressignificados, reacentuados a cada enunciação, já que novos acentos valorativos se inscrevem nas práticas discursivas, passando a refletir a individualidade do falante, seu estilo pessoal, na relação com o outro (discursos e sujeitos).

Na materialização dos gêneros, além da forma composicional, relativa à sua organização, é fundamental a forma arquitetônica, em sua singularidade, no que diz respeito a valorações entre locutor, objeto de dizer e interlocutor. Seguindo o pensamento bakhtiniano, Sobral (2010, p. 77) observa que, enquanto a forma composicional se vincula com as estruturas textuais, "a forma arquitetônica se vincula com o projeto enunciativo do autor, com o tipo de relação com o interlocutor que ele propõe”. $\mathrm{Na}$ interação entre as formas, a arquitetônica, com seu jogo de valorações, determina a composição, podendo se realizar de várias maneiras. 
A entonação, materializada pelos acentos valorativos, tons, "sempre se encontra no limite entre o verbal e o extraverbal, entre o dito e o não dito" (VOLOCHÍNOV/ BAKHTIN, 1926/2011, p. 160). É pela entonação, que é ativa e social, que se observa a relação indissolúvel da palavra com o acontecimento da vida, do locutor com o interlocutor e do locutor com o objeto do dizer, o que aponta para o fato de que a enunciação concreta "nasce, vive e morre no processo de interação social dos participantes da enunciação" (p. 165). São as particularidades da interação que vão definir o modo do dizer e produzir uns ou outros sentidos.

A palavra, nessa perspectiva, ao ser acentuada valorativamente, é o resultado da relação entre o locutor e seus interlocutores, tendo em vista interações já realizadas e a se concretizarem. Exprime a posição de "um" em relação ao "outro": "na palavra me dou forma a mim mesmo do ponto de vista do outro [...] do ponto de vista de minha comunidade" (VOLOŠINOV, 1929/2010, p. 299). A palavra, além de ser um território partilhado pelo locutor e o interlocutor, é um signo ideológico por excelência e, como signo, nela "se entrecruzam acentos de orientação diferente" (p. 161). Ao refletir e refratar, o signo imprime uma dialética interna, uma pluriacentuação social, tecida pela dinâmica coexistência de diferenças, fazendo reverberar valores e posições ideológicas.

A relação com o outro se revela, como afirma Bakhtin (1959-1961/2003, p. 330), na tessitura do discurso verbal, cujas palavras são repletas de voz (pontos de vista, visões de mundo, posições), já que "não existem palavras sem voz, palavras de ninguém. Em cada palavra há vozes às vezes infinitamente distantes, anônimas [...] quase imperceptíveis, e vozes próximas, que soam concomitantemente". Para tratar do discurso, entendido como "a língua em sua integridade concreta e viva", Bakhtin centra atenção nas relações dialógicas (relações de sentido), sem desconsiderar as análises linguísticas e seus resultados (relações lógicas) (BAKHTIN, (1929)1963/1997, p. 181$){ }^{5}$

No ensaio $O$ discurso no romance (1934-1935), que integra Teoria do romance I: A estilística, Bakhtin (1930-1936/2015) discute a questão da pluralidade de vozes no discurso. Ao desenvolver a noção de heterodiscurso, destacando o heterodiscurso dialogizado como "o autêntico meio da enunciação, no qual ela se forma e vive" (p. 42), observa a importância de se analisar a relação entre as vozes discursivas, de modo que se perceba não só a diversidade de vozes mas também o diálogo instaurado entre elas. ${ }^{6}$ No heterodiscurso, há uma tensão entre forças, as centrípetas e as centrífugas, que garantem dinamicidade à enunciação: enquanto as primeiras procuram resistir às divergências, as segundas se empenham em manter a variedade, as diferenças.

O discurso, ao voltar-se para o objeto, encontra-o envolvido por diversas ava- 
liações, mais ou menos obscuras, mais ou menos aparentes. Nesse meio dialogizado, agitado e tenso de avaliações, o discurso entrelaça-se com uns, afasta-se de outros, cruza-se com terceiros. Em um jogo de claro-escuro, o enunciado, surgido em um momento histórico e em um meio social determinado, toca em

[...] milhares de linhas dialógicas vivas envoltas pela consciência socioideológica no entorno de um dado objeto da enunciação, não [podendo] deixar de ser participante ativo do diálogo social (BAKHTIN, 19301936/2015, p. 49).

No cenário dos variados discursos em circulação, o pensador russo enfatiza a necessidade de se estudar as complexas relações com a palavra do outro por diferentes razões (BAKHTIN, 19701971/2003, p. 379-380). Dentre elas, afirma que vivemos em "um mundo de palavras do outro": a nossa vida "é reação às palavras do outro (uma reação infinitamente diversificada), a começar pela assimilação delas (no processo de domínio inicial do discurso) e terminando na assimilação das riquezas da cultura humana (expressas em palavras ou em outros materiais semióticos)". Ampliando sua reflexão, observa que a palavra do outro exige do sujeito "a tarefa especial de compreendê-la". Destaca ainda o filósofo russo que há "uma tensa luta dialógica" (grifo nosso) nas fronteiras entre as "próprias palavras" e as "palavras do outro" que podem se confundir, o que exige análise e reflexão do "complexo acontecimento do encontro e da interação com a palavra do outro".
Considerando o esboço teórico apresentado, em que discutimos características da constituição dialógica do discurso, passamos a contextualizar a situação em que os enunciados a serem analisados foram produzidos.

\section{Contexto de produção, circulação e recepção do discurso}

As duas charges que compõem este estudo são de autoria do cartunista Iotti e foram publicadas em Zero Hora, jornal de maior circulação no Rio Grande do Sul, que faz parte do Grupo RBS, afiliado da Rede Globo. A primeira charge, publicada no dia 30 de dezembro de 2011, em uma arquitetônica mais complexa comparada à segunda, ilustra a problemática relativa à leitura, tendo em vista compreensões não esperadas por parte do público leitor, o que aponta para a necessidade de desenvolver práticas de ensino voltadas para a formação de leitores proficientes, que entendam o funcionamento do discurso e os sentidos que são produzidos. A segunda charge, publicada no dia 05 de janeiro de 2012, emerge como um discurso-resposta à primeira, em uma arquitetônica acessível a distintos leitores, buscando mostrar a posição do cartunista Iotti para o público que não entendeu a primeira charge.

Quanto à contextualização da primeira charge, que trata do abandono de um cão na estrada e que acabou originando a segunda charge, conforme o Blog do 
Editor ${ }^{7}$, do jornal Zero Hora, consultado no dia 12 de agosto de 2012, o assunto da charge "foi o campeão em repercussão na primeira semana de 2012", ao provocar uma comoção não esperada dos leitores do jornal. Segundo o Blog, "somente no e-mail do Relacionamento com o Leitor, 42 mensagens" foram recebidas. Das quatro mensagens visualizadas no $B l o g$, três delas, incluindo duas professoras, criticam o cartunista por "mostrar o cãozinho sendo largado na estrada", como se estivesse "promovendo o abandono dos animais". Somente uma mensagem, de uma microempresária, parabeniza o chargista por retratar o que chama de "triste realidade, muitas vezes até negada, das famílias com os animais de estimação!". Diante da repercussão da charge e da leitura equivocada difundida, o cartunista se manifestou dizendo que seu objetivo era justamente outro: "se mostrar favorável aos animais".

O Blog O Grito do Bicho ${ }^{8}$, que tem como propósito lutar pelos direitos dos animais, também teve como pauta de discussão, nos primeiros dias de 2012, a charge de Iotti. Das 37 mensagens visualizadas no Blog, no dia 12 de agosto de 2012, poucas, não mais de 10 , entenderam o propósito da charge e a crítica que estava sendo feita. Devido à repercussão no $B l o g, o$ cartunista Iotti também se manifestou:

Antes de tudo gostaria de registrar meu espanto com a interpretação que foi dada à charge. A minha ideia era exatamente oposta a essa. Aideia da charge é uma DENÚNCIA a essa barbaridade que acontece nessa época do ano (grifo do cartunista).
É possível observar, a partir da polêmica difundida nos Blogs consultados, que parece haver uma lacuna na formação dos leitores, já que parte dos autores das mensagens veiculadas nos Blogs afirmou que o chargista estava incentivando o abandono de animais. Essa leitura pode ser considerada inadequada em função da arquitetônica da charge, que instaura um conjunto de possibilidades de sentido, não contemplando essa que foi propagada nos Blogs. ${ }^{9}$

Tendo em vista esse fato concreto, que demonstra problemas de compreensão do que é lido e, ao mesmo tempo, um modo de simplificação da linguagem, faz-se necessário trazer para discussão questionamentos sobre, por um lado, a falta de reflexão acerca da complexidade da linguagem e, por outro, a necessidade de postura crítica frente aos discursos da contemporaneidade. Parece que, para os autores das mensagens dos Blogs, o importante era defender sua causa própria, a proteção aos animais, sem se questionarem sobre o contexto de produção do que estava sendo lido, que não permite a leitura que foi feita: Quem produziu? Para quem? Com que finalidade? Em que momento? Em que veículo foi publicado? Que gênero do discurso é esse? Se essas questões básicas fossem, de alguma forma, objeto de reflexão, a leitura da charge seria outra.

Considerando o chamado pragmatismo da contemporaneidade, entendido como uma dinamicidade desenfreada, Amorim (2007) propõe a sistematização 
do conhecimento, de modo a instaurar a alteridade, fundamental para a atividade crítica. É, nessa direção, que entendemos que a leitura deve ser ensinada, ou seja, deve ser objeto de reflexão nos diferentes níveis de ensino. O desenvolvimento da atividade crítica da leitura exige que o aluno aprenda a refletir sobre o funcionamento do discurso e sobre como os sentidos são produzidos. Nesse cenário, nós, como pesquisadores e professores da área de Estudos da Linguagem, temos o compromisso de desenvolver pesquisas sobre esse tema que possam oferecer subsídios para o ensino de leitura e produção de textos.

Passamos a reflexões sobre como os sentidos são produzidos na primeira charge, que gerou variadas leituras, de modo a ilustrar de que maneira a teoria bakhtiniana pode contribuir para a análise de gêneros midiáticos mais ou menos complexos e, consequentemente, colaborar para a formação de leitores proficientes. Para tanto, tomando como pressuposto que há uma relação de tensão entre discursos e que é importante considerá-la nas práticas de leitura, são postos em discussão aspectos da constituição enunciativa do discurso. Em seguida, são apresentadas breves considerações sobre a segunda charge, produzida como resposta aos leitores de Zero Hora, buscando desenvolver reflexões sobre as diferenciadas arquitetônicas entre ambas e a consequente contribuição para a formação de leitor competente.

\section{O gênero charge para além das generalizações: questões de leitura}

Apresentamos a seguir reflexões sobre a primeira charge. ${ }^{10}$

Figura 1 - Charge 1

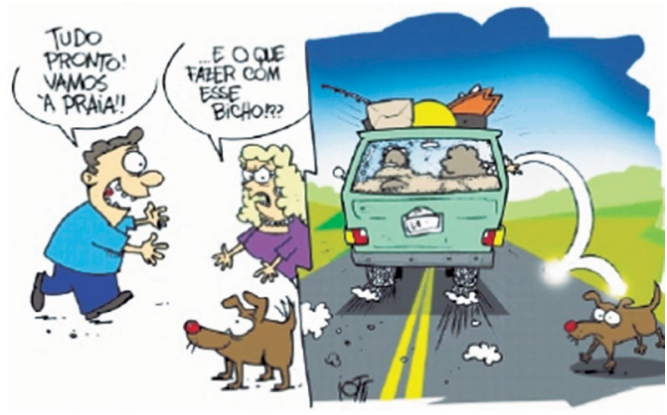

Fonte: Zero Hora, 30/12/2011.

Para compreender o funcionamento do discurso e a construção de sentidos, é relevante considerar o gênero discursivo que está sendo mobilizado em relação à esfera de atividade que o organiza. Desse modo, consideramos a esfera midiática, mais especificamente a jornalística, importante para compreender aspectos da produção, circulação e recepção de gêneros na contemporaneidade, como é o caso da charge.

Nesse contexto, há de se observar que diferentes gêneros exigem diferentes leituras. Em sentido amplo, há gêneros mais "informativos", como notícia e reportagem, e outros mais "opinativos", como editorial, artigo de opinião, crônica jornalística e charge. ${ }^{11}$ Embora se saiba que todos resultam de uma construção discursiva e, portanto, são produzidos por 
sujeitos situados em um espaço histórico-social considerando seus interlocutores, a partir de um determinado projeto enunciativo, cada gênero tem características próprias, que geram efeitos de sentidos diversos em suas materializações.

Não se pode, por exemplo, ler uma notícia da mesma forma que se lê um editorial, ou seja, cada gênero tem seu projeto enunciativo, uma relação de interlocução própria, além de características relativas ao tema, ao estilo e à forma composicional. Ainda que na notícia haja escolhas do jornalista no que se refere à seleção da informação, dos entrevistados e dos recursos linguísticos, entre outros elementos, a notícia, para ser reconhecida como tal, deve criar efeito de verdade e de objetividade. Já o editorial, como compreende Charaudeau (2009, p. 235), tem características de "acontecimento comentado" ao trazer um ponto de vista sobre um acontecimento da atualidade considerado importante, no que se refere ao domínio político e social.

Pode ocorrer certa dificuldade em reconhecer um determinado gênero, em alguns casos, considerando a aproximação entre alguns deles ou ainda a sua potencialidade de plasticidade e hibridização. Por exemplo, pode ocorrer alguma dificuldade para diferenciar um artigo de opinião de uma crônica jornalística, já que ambos problematizam um dado fato ou assunto e se organizam de modo a discutir e mostrar a opinião do locutor sobre o problema apresentado. Nessa mesma direção, pode ocorrer al- guma dificuldade em distinguir o gênero charge do gênero tira, ambos publicados em jornais diários. Não basta, por exemplo, analisar a forma composicional do gênero quanto ao número de quadrinhos para reconhecê-lo. Ler uma charge como uma tira vai resultar em compreensões equivocadas, pois são projetos enunciativos diferentes que exigem diferenciadas atitudes ativas do leitor. Logo, a questão é bem mais complexa do que aparenta, $\mathrm{e}$ uma análise superficial pode incorrer em problemas de compreensão dos sentidos.

Considerando o cenário apresentado no que se refere a questões de leitura, passemos a observar a Charge 1 , a partir de duas instâncias enunciativas articuladas, as quais devem ser consideradas para o entendimento dos sentidos construídos no discurso: (i) uma em relação ao locutor projetado no discurso (o cartunista) e o interlocutor (o leitor presumido da charge) e (ii) outra em relação ao locutor no interior do discurso, o homem, e o respectivo interlocutor, a mulher. Essas duas instâncias devem ser analisadas para se compreender os distintos projetos enunciativos postos em cena e a construção de sentidos que resulta do confronto entre ambos. Se o leitor atentar apenas para o projeto enunciativo dos interlocutores no interior do discurso, desvinculado da situação concreta de produção, $o$ gênero charge em foco, que se integra ao fluxo da comunicação verbo-social, não entenderá o sentido da charge. Ficar apenas na superfície do discurso, a linguagem verbal e os aspectos visuais, 
resulta numa leitura inadequada, como a feita por parte dos autores das mensagens dos Blogs consultados. É necessário ir além do dito, do visível, observando que há uma relação de tensão entre o que é mostrado e o que não é aparente, mas decisivo para a produção dos sentidos. Na mesma direção, não identificar o projeto enunciativo do locutor da charge e o contexto histórico-social de produção do discurso resulta no não entendimento da crítica efetuada.

O contexto extraverbal, como esclarece Volochínov/Bakhtin (1926/2011, p. 156), compõe-se de três aspectos: (i) um horizonte espacial compartilhado pelos falantes; (ii) o conhecimento e a compreensão comum da situação; e (iii) a valoração compartilhada da situação (grifo nosso). Se essas três dimensões podem ser facilmente apreendidas na instância enunciativa interna, no que diz respeito à interação entre o homem e a mulher, que se entendem na troca interlocutiva, o mesmo não se pode dizer no âmbito da instância enunciativa externa, relação entre o cartunista e parte dos leitores da charge. O horizonte espacial não é compartilhado com todos os interlocutores. Também não há um conhecimento e compreensão comum $d a$ situação e nem uma valoração compartilhada da situação. A parte extraverbal, subentendida, que deveria ser reconhecida pelos interlocutores, não o é; por isso, o sentido não é compreendido.

Observa-se assim a importância de se perceber que a tensão entre o dito e o não dito faz parte da produção dos sentidos. Logo, a palavra, seguindo Volochínov/ Bakhtin (1926/2011), não é um reflexo direto da situação extraverbal assim como a situação extraverbal não é uma força mecânica externa da enunciação. A situação é parte constitutiva necessária da composição semântica. Nessa perspectiva, para a compreensão dos sentidos da Charge 1, faz-se necessário entender que o locutor, ao abordar um flagrante do cotidiano, ilustrado por um casal caricaturado que abandona seu cachorro pelo afã de ir para a praia, está se posicionando contra essa prática irresponsável, isto é, seu projeto enunciativo é contestar, ser crítico, sobre um fato em voga, noticiado pela mídia à época da publicação (30/12/2011).

Em uma rápida busca na Internet, referente aos dias 29 e 30 de dezembro de 2011, foram encontradas várias notícias sobre o Rio Grande do Sul, tendo como tema o litoral em consonância com o final de ano (que coincidiu com um final de semana) e o início das férias. Também, em 30 de dezembro 12, foi publicado, no Blog do Editor, que nesse dia começava a "cobertura Verão 2012 de Zero Hora, direto da praia de Capão da Canoa, onde fica a casa do grupo RBS no litoral" (acesso: 14/08/2012). Se, por um lado, na ocasião da publicação da charge, o litoral estava em primeira pauta, por outro, também figurava nas matérias da mídia a questão dos animais abandonados nas estradas. No mesmo dia da publicação da charge, o G1, Globo.com ${ }^{12}$, noticiava uma 
"Campanha contra abandono de animais nas estradas" no Rio Grande do Sul. Conforme a notícia, foi firmada uma parceria no dia 29/12/2012, "entre a Prefeitura de Porto Alegre e a concessionária Triunfo-Concepa [com] o objetivo de combater o abandono de animais nas estradas". A campanha, além de distribuir materiais informativos nos pedágios nas rodovias, recolheria os animais encontrados para castração e atendimento veterinário. Também os moradores seriam orientados sobre a melhor maneira de cuidar dos seus bichos de estimação. Nessa notícia, o prefeito de Porto Alegre, José Fortunati, alertou sobre a adoção responsável: "Os animais merecem nosso respeito e cuidado. As famílias devem buscar uma alternativa, planejar suas férias sem esquecer os animais de estimação".

Desenvolvendo a reflexão sobre particularidades do gênero charge, destaca-se que, para o entendimento da crítica contra a prática de abandono de animais, tematizada pela Charge 1, o leitor necessita não só estar a par dos acontecimentos da atualidade mas também ter conhecimento de que a charge, como gênero do discurso, tem como projeto enunciativo pôr em evidência, de diferentes modos, fatos da atualidade para ressignificá-los criticamente. Logo, faz-se necessário entender que o locutor na charge em foco reveste com seu acento valorativo o ato do casal, fazendo fluir um confronto de vozes engendrado na tessitura do discurso. Entre aspectos do reflexo e da refração do signo, percebe-se que a refração, uma espécie de orientação da palavra em "forma de raio", reverbera um jogo vivo e singular de sentidos (BAKHTIN, 1930-1936/2015). Como o casal caricaturado diz e faz o contrário do que o locutor da charge defende, são, portanto, enunciações com orientações axiológicas opostas, cria-se um efeito de ironia, uma crítica irônica, que necessita de uma reflexão apurada, uma atitude responsiva ativa do leitor para compreender o sentido produzido.

Essas ponderações iniciais sinalizam o quanto seria importante no ensino de leitura explorar análises, cotejando variadas materializações de um mesmo gênero, como é o caso da charge, para assim compreender os diversos funcionamentos do discurso para além de generalizações composicionais. Também, nessa direção, seria válida a reflexão sobre aproximações e distanciamentos entre gêneros, de certo modo, considerados aparentados, como a charge e a tira. Faraco (2009, p. 129), discutindo a questão dos gêneros, observa que o teórico russo "não se propõe a fixar o que se move, estancar o que flui, nem estabelecer limites claros para aquilo que é necessariamente impreciso, já que intrinsecamente vinculado à contingência das atividades humanas". No entanto, "as atividades humanas não são nem totalmente previsíveis [...], nem totalmente casuais", o que significa que há recorrências organizadoras das atividades, que orientam para o enfrentamento do novo, inter-relacionando a memória e o acontecimento. 
Nesse contexto, destaca-se, como explica Bakhtin (1924/1998, p. 25), diferenças entre a forma arquitetônica e a forma composicional. Enquanto a arquitetônica volta-se para a "existência estética na sua singularidade", contemplando 0 acontecimento de vida particular, social, histórica, etc., a composicional organiza o material de modo utilitário, servindo de realização à tarefa arquitetônica. Em outras palavras, a forma arquitetônica, ao determinar a escolha da forma composicional, com ela se articula. De acordo com Sobral (2010, p. 77), "a atividade do autor incide primordialmente sobre a forma arquitetônica, que é a organização do discurso [...], em termos de uma dada avaliação do discurso pelo autor e de sua recepção ativa por um ouvinte", valendo-se para tanto de uma forma composicional.

Considerando a Charge 1, pode-se perceber que a relação axiológica com o objeto do dizer, o abandono do cão, e os interlocutores, a partir de recursos linguísticos e composicionais, instaurou uma forma arquitetônica singular, já que a charge, como enunciado, é construída como uma resposta, uma atitude responsiva ativa do locutor, frente à atualidade. Entender o tenso diálogo com os discursos que são convocados e com as vozes discursivas que se fazem ouvir é de suma importância para a compreensão dos sentidos.

Na materialidade discursiva, incluindo a articulação entre aspectos verbais e visuais, as escolhas do locutor revelam, a partir de seu ponto de vista, aspectos do estilo, da forma composicional e do tema do gênero. Na charge em foco, o estilo e a forma composicional podem ser observados a partir de valorações na constituição do enunciado verbo-visual em dois momentos. $\mathrm{O}$ primeiro contempla aspectos da oralidade, no que tange à fala do homem para a mulher ("Tudo pronto! Vamos à praia!!") e à fala da mulher para o homem, referindo-se ao cachorro, que participa da cena enunciativa (“... E o que fazer com esse bicho?”). Junto aos aspectos da oralidade engendram-se expressões corporais do casal (um em direção ao outro), faciais (olhos arregalados, boca aberta) e gestuais (mão abertas), expressando a necessidade de resolver com rapidez o problema relativo ao que fazer com o cachorro, que observa a discussão. $\mathrm{O}$ segundo momento, materializado por aspectos visuais, mostra o casal no carro, dirigindo-se ao litoral e jogando o cão na estrada. $O$ carro em movimento de ida, carregado com apetrechos de praia (malas, prancha, caniço de pesca, etc.), contrapõe-se ao movimento do cão, que, ao ser jogado na estrada asfaltada, parece buscar um refúgio, como se nota pela expressão do olhar e do corpo.

O desprezo pelo animal pode ser visto em duas instâncias articuladas: no enunciado da mulher, ao ser convocada a se dirigir à praia (“[...] E o que fazer com esse bicho?"), construído em forma de pergunta, uma materialização de dúvida, e constituído pela designação, com tom avaliativo negativo, "esse bicho", para se referir ao cão, e no enunciado visual, em que o cachorro é jogado para fora do carro. 
O problema do casal, no caso o cachorro, que poderia atrapalhar a viagem ao litoral, é resolvido de forma simples, o animal é descartado, abandonado. Podemos perceber, a partir dessas ponderações, que, na produção dos sentidos, a entonação expressa tanto a valoração da situação, o problema a ser resolvido e o descarte do cachorro, quanto a valoração do auditório, ou seja, o público para quem é dirigida a charge. Em cada elemento verbo-visual na sua relação com outros elementos e com o todo, incluindo o contexto extraverbal, os sentidos vão sendo construídos singularmente na enunciação.

Nessa tessitura, o tema vai se revelando, o que exige do leitor atentar para como os acentos valorativos orientam socialmente as relações dialógicas que emergem entre ditos e não ditos. Compreender a enunciação de outrem, de acordo com Bakhtin/Volochinov (1929/1995), significa orientar-se em relação a ela, encontrar o seu lugar adequado em um dado contexto, fazendo corresponder outras enunciações, contrapalavras. É somente por uma atitude responsiva ativa que se pode apreender o tema, o qual, sendo dinâmico, necessita de um processo evolutivo que ultrapasse os limites da significação (elementos reiteráveis) para a compreensão da enunciação completa. Assim, na enunciação da Charge 1, estabelecendo relação com aspectos sociais e culturais, pode-se ponderar que, enquanto o casal é visto como um protótipo da sociedade contemporânea, com atitudes egoístas, voltadas para o seu próprio bem-estar, com preocupações com o aqui e agora e com relações passageiras, o cachorro, ao ser apresentado como um objeto descartável, que pode ser rejeitado quando, de algum modo, interferir no planejamento familiar, é focalizado como um ser que necessita de proteção. Observar essas características implica reconhecer tensas relações com discursos da atualidade, sinalizados na materialidade discursiva e decisivos para a compreensão dos sentidos. O tema, desse modo, pode ser resumido de forma a manifestar a posição do locutor da charge, que faz uma crítica contundente ao abandono dos animais, à falta de responsabilidade de quem cria os bichos e não os protege, problema que emerge principalmente no período de verão, quando, culturalmente, as pessoas costumam ir à praia.

Na produção dos sentidos, seguindo a teoria bakhtiniana, todo enunciado verbal e não verbal, introduzido em dado discurso, é reavaliado, acentuado axiologicamente pelo locutor do discurso em outra condição concreta de produção, diferente da de sua procedência. Sob esse prisma, assim como o discurso do outro pode aparecer em forma de "repetição" para concordar com um dizer, pode também ser uma "repetição" para discordar do dizer. Cabe ao analista, o leitor, analisar os acentos valorativos engendrados no discurso para perceber efeitos de sentidos criados, que podem revelar ironia, indignação, humor, deboche, zombaria, etc.

Para a compreensão do funcionamento dos sentidos, a relação de tensão entre 
discursos, observada na charge em foco, deve fazer emergir relações dialógicas diversas, pois, ao enunciar, o locutor da charge entra em relação de aliança com os protetores dos animais e com os próprios animais, que necessitam de proteção, e, ao mesmo tempo, entra em relação de confronto com os que não protegem os animais e os que os abandonam. $\mathrm{O}$ entendimento desse tenso diálogo de vozes remete à não coincidência do discurso consigo mesmo, ou seja, sempre há outras relações a serem percebidas para se entender a construção dos sentidos, já que a linguagem é opaca e complexa. Se do ponto de vista da pesquisa, cabe ao pesquisador desvendar essa engrenagem a partir de um estudo teórico aprofundado, do ponto de vista da leitura, cabe ao leitor analisar a opacidade da linguagem e seus recursos verbo-visuais para entender os sentidos produzidos. No caso, para parte dos leitores que se manifestou nos Blogs consultados, ao que parece, a linguagem foi considerada transparente, como se o sentido estivesse posto e não precisasse de reflexão para apreendê-lo.

Destaca-se, ainda, que, na constituição do discurso, há uma projeção ao destinatário, no sentido de considerar o grau de informação que ele tem sobre o objeto do dizer. No caso da Charge 1 , é possível dizer, a partir da construção enunciativa, que o locutor espera que o interlocutor esteja a par do que está acontecendo na atualidade, no que se refere ao grande movimento de famílias se dirigindo ao litoral gaúcho no final de ano e ao problema da falta de responsabilidade no cuidado com os animais de estimação nessa época de veraneio. Esse grau de informação esperado interfere na composição, no estilo e na expressividade do enunciado. Para tanto, deve-se observar o flagrante (da vida) posto em evidência, de modo caricatural, em um dado momento histórico, que, juntamente com o projeto enunciativo do locutor, o estilo e a forma composicional, revela aspectos da dinamicidade do tema e do gênero em uma arquitetônica única.

Para concluir essa reflexão inicial sobre a Charge 1 , destacamos a empatia e a exotopia, propostas por Bakhtin (1922-1924/2003), como movimentos importantes a serem considerados para o exercício de leitura. Espera-se que o leitor, no interdependente e tenso movimento entre a aproximação (empatia) e o distanciamento (exotopia) ao objeto de compreensão, faça o necessário retorno para o acabamento do compreendido. Tal acabamento acontece a partir da relação de alteridade, necessária para a criação de conhecimento. Associando essa reflexão às leituras da Charge 1, postadas nos Blogs consultados, podemos entender que parece ter havido, por parte de leitores, uma espécie de empatia duradoura em relação ao objeto do discurso, o abandono do animal. Em outras palavras, alguns leitores se aproximaram intensamente do sofrimento do cachorro que foi abandonado, o que teria prejudicado o retorno ao lugar de origem, de observador externo, o lugar 
exotópico, necessário, que convoca um excedente de visão para ver além do todo. A partir dessa hipótese, seria possível explicar, de certa forma, por que a charge foi polemizada. O leitor teria se fixado apenas na instância enunciativa interna, a interlocução entre o homem e a mulher e o abandono do cachorro, e não teria retornado à instância externa, relação chargista e leitor, articulando as partes e o todo.

Passemos à segunda charge:

Figura 2 - Charge 2

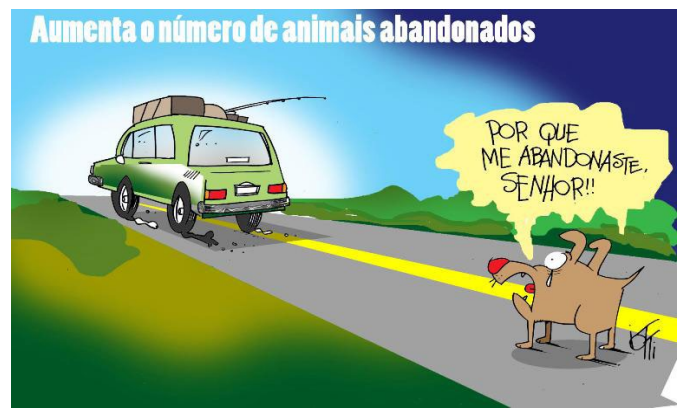

Fonte: Zero Hora, 05/01/2012.

Diante da polêmica gerada com a publicação da Charge 1, Iotti publica a Charge 2, buscando responder à insatisfação dos leitores..$^{13}$ A segunda charge, colocada em relação dialógica com a primeira, aponta para a diferença entre os funcionamentos discursivos, que remetem, dentre outros aspectos, à questão da hipótese forte e hipótese fraca levantada por Charaudeau (2009), no que diz respeito às projeções aos destinatários. É possível perceber, nesse contexto, que a primeira charge exige mais esclarecimento por parte dos interlocutores, enquanto que a segunda, ao explorar os sentidos de modo mais aparente, exige menos dos leitores.

Na produção do enunciado, como destaca Bakhtin (1952-1953/1992, p. 320321 ), o locutor sempre leva em conta seu destinatário, e essa percepção vai influenciar nas escolhas, interferindo na composição e estilo. Nessa perspectiva, a forma arquitetônica da segunda charge, considerando o projeto enunciativo do locutor e a projeção avaliativa aos interlocutores, difere-se da primeira charge, valendo-se de uma forma composicional e estilo também diferentes. Os elementos verbais e visuais que constituem a Charge 2 são organizados de modo a não exigirem uma reflexão aprofundada para a compreensão dos sentidos produzidos, o que se justifica, de certa maneira, pelo fato de o cartunista publicar a charge como resposta à polêmica gerada. Em outras palavras, uma charge de fácil compreensão garantiria maior abrangência e resolveria possíveis mal-entendidos.

A organização verbo-visual da charge, concentrada em um retângulo de linhas retas, demarcadas, diferentemente da Charge 1, que não tem demarcação linear, apresenta uma espécie de título: "Aumenta o número de animais abandonados". Este enunciado verbal é acentuado valorativamente de modo a orientar a posição axiológica do locutor no que se refere à crítica contra o abandono dos animais. $\mathrm{O}$ enunciado também faz alusão à manchete de notícia jornalística, criando um efeito de informação sobre 
o aumento do abandono de animais, o que torna mais clara a posição assumida pelo locutor e intensifica o tom crítico no conjunto da charge.

Abaixo, em destaque, aparecem o carro e o cão. $\mathrm{O}$ carro em movimento, semelhante ao da Charge 1, caricaturado com bagagens e apetrechos de praia, se dirige ao litoral. $\mathrm{O}$ cachorro abandonado na estrada, o mesmo animal da Charge 1, é caricaturado com expressão de tristeza, como se pode observar nos olhos arregalados com lágrimas, orelhas erguidas, boca expressando movimento de fala. Diferentemente do que na Charge 1 , que somente o casal fala, na charge 2 , a fala é dada ao cão; apenas ele fala, ele é personificado. Olhando para o carro que se distancia, o cão enuncia, em tom exclamativo, "Por que me abandonaste, senhor!!".

Ainda que a constituição dos sentidos seja mais aparente na Charge 2, se relacionada à Charge 1 , devemos reparar discursos convocados, vozes em interação, a partir da situação concreta de produção. Sob essa perspectiva, percebemos que o enunciado de responsabilidade do cachorro apresenta índices que permitem observar o diálogo com $o$ enunciado da Bíblia, referente à palavra de Jesus, que, na cruz, em tom de interrogação, enuncia: "Meu Deus, por que me abandonaste?"14 É importante notar que o diálogo entre os dois enunciados cria um efeito de sentido que intensifica a valoração sobre a crítica ao abandono do cachorro. Dito de outro modo, o sentimento de abandono do cão é potencia- lizado ao remeter ao sofrimento também de abandono de Jesus.

Observando os acentos de valor na constituição do discurso da charge, percebemos a relação do locutor com o interlocutor, com o objeto do dizer e com o contexto extraverbal (horizonte espacial, conhecimento, compreensão e valoração da situação), que é compartilhado com os leitores, facilitando a compreensão dos sentidos produzidos.

\section{Considerações finais}

No presente artigo, trouxemos para debate a problemática da leitura a partir de um caso concreto, a polêmica gerada pela publicação de uma charge, que provocou a publicação de uma segunda charge pelo mesmo cartunista. Nesse cenário, discutimos, a partir da abordagem dialógica, como os sentidos são produzidos singularmente em cada uma das charges, o que nos permitiu aprofundar questões acerca da complexidade da linguagem e da constituição dos gêneros do discurso. Ao considerar a charge para além das generalizações, buscamos ampliar e verticalizar a reflexão de modo a iluminar, em cada enunciação concreta, as particularidades na tensão com as recorrências.

As reflexões desenvolvidas também trouxeram luz sobre a importância de se discutir acerca da formação do leitor na contemporaneidade, especialmente ao problematizarmos a distância entre a informação, como a grande quantidade de discursos que circulam em diferentes 
mídias, e a formação, consistência do conhecimento adquirido. Leituras rápidas, sem o devido aprofundamento, ou ainda leituras que consideram a linguagem apenas na dimensão do dito, sem as devidas articulações com o contexto e as relações com outros discursos, alertam para o imediatismo da contemporaneidade no que se refere ao não reconhecimento do outro, à simplificação do complexo.

Pelas análises efetuadas, foi possível perceber que a primeira charge, comparada à segunda, exige uma maior atenção dos leitores quanto à percepção da construção dos sentidos, não só em relação aos acontecimentos sociais do momento da produção do discurso, mas também em relação ao reconhecimento do gênero e da articulação entre o verbal e o extraverbal. Muitos leitores, como alguns que se manifestaram nos Blogs visitados, não compartilharam com o locutor do mesmo horizonte espacial, da situação e da valoração. A forma arquitetônica da charge, que reclama a observação das relações valorativas e do projeto enunciativo na singularidade da materialização do discurso, não foi apreendida, o que gerou leituras inadequadas. Com isso, os sentidos não foram compartilhados. Faltou o reconhecimento das avaliações subentendidas. Já, na segunda charge, o locutor, ao perceber a incomodação dos interlocutores, numa atitude ativa responsiva, muda a entonação, e com isso a forma arquitetônica, ao construir a enunciação de outra maneira, visando, como entende Ponzio (2011, p. 27), contar com um "subentendido apoio coral" dos interlocutores.
De qualquer maneira, na relação entre o locutor e a projeção aos interlocutores, pensando no processo interlocutivo instaurado em cada uma das charges, ou na relação entre o chargista e os leitores, no que tange à questão de leitura propriamente, é importante destacar os diferentes horizontes de valor, as diferentes projeções de quem ocupa lugar único, insubstituível. Sob esse aspecto, o movimento de aproximação, juntamente com o necessário movimento de afastamento, exotopia, é fundamental para se perceber as relações entre as partes e o todo, evitando a percepção de uma só dimensão do discurso. Para Bakhtin,

[...] compreender um objeto significa compreender meu dever em relação a ele (a orientação que preciso assumir em relação a ele), compreendê-lo em relação a mim na singularidade do existir-evento: o que pressupõe a minha participação responsável [...] (1920-1924/2010, p. 66).

A compreensão como um ato ético, responsável, é bastante produtiva para as reflexões sobre o ato de leitura.

Desse modo, com o desenvolvimento deste trabalho, pudemos constatar o potencial da teoria bakhtiniana como referencial para o ensino de leitura, especialmente por oferecer subsídios sobre como os sentidos são construídos nas produções discursivas, incluindo a singular participação de dois centros de valor: o locutor e o interlocutor. Resumidamente, ao levantarmos questões sobre a produção dos sentidos das charges, pudemos reiterar, dentre outros pontos, a necessidade de considerar, na compreensão dos 
sentidos, a enunciação em sua concretude, no processo de interação social:

Ao arrancar a enunciação deste chão real que a alimenta, perdemos a chave que abre o acesso de compreensão tanto de sua forma quanto de seu sentido; em nossas mãos ficam ou uma moldura linguística abstrata, ou um esquema abstrato de sentido [...] (VOLOCHÍNOV/BAKHTIN, 1926/2011, p. 165).

\section{Discours, médias et production des sens: des questions de lecture et de formation dans la contemporanéité}

\section{Résumé}

Considérant la pluralité des discours qui circulent dans les médias et le besoin de comprendre les fonctionnements concernant la construction des sens, nous réfléchissons à propos de deux charges qui illustrent la problématique contemporaine de la lecture. La première charge, publiée le 30 décembre 2011, a produit des réactions diverses chez les lecteurs, ce qui a provoqué la publication d'une autre charge le 5 janvier 2012. Cet article qui a le but de présenter des réflexions à propos de la façon dont les sens sont produits par les charges sélectionnées, prétend montrer comment la théorie bakhtinienne qui soutient cette réflexion peut contribuer à l'analyse des genres des médias plus ou moins complexes et, par conséquent, comment elle peut collaborer à la formation de lecteurs compétents.

Mots-clés: Lecture. Charge. Production des sens. Tension. Téorie dialogique du discours.

\section{Notas}

1 A problemática desenvolvida neste artigo integra o projeto em desenvolvimento.

2 O Círculo de Bakhtin é formado por um grupo de estudiosos, cujos principais integrantes da área da linguagem são M. Bakhtin, V. N. Volochinov e P.N. Medvedev, que tinham interesses filosóficos comuns e se reuniam para debater suas ideias, principalmente entre 1919 e 1929, na Rússia (CLARK e HOLQUIST, 1984/1998; MORSON e EMERSON, 1990/2008). Embora atualmente se tenha clareza dos autores das obras do Círculo, neste artigo utilizo os nomes conforme constam dos volumes consultados. Desse modo, mesmo tendo ciência de que, por exemplo, o livro Marxismo e filosofia da linguagem é de autoria de Volochinov, uso Vološinov (1929/2010) para a tradução do francês e Bakhtin/Volochinov (1929/1995) para a tradução do português. Com relação às datas, antes da barra, informo o ano da primeira publicação e/ou o período da escrita do texto; após a barra, indico o ano da edição consultada. Para referir-me às reflexões teórico-metodológicas do Círculo, utilizo expressões como teoria bakhtiniana, pensamento bakhtiniano ou teoria dialógica do discurso, tendo como pressuposto que as ideias são representativas do grupo.

3 Nos trabalhos de Amorim (1996, 2001, 2007), que enfocam as contribuições da teoria dialógica bakhtiniana, encontramos reflexões importantes sobre a tensão existente na produção dos sentidos, focalizando em especial a tensão como relação entre as diferenças, no que se refere a pesquisas desenvolvidas nas Ciências Humanas e na Educação.

4 As rubricas "enunciação" e "enunciado", na obra bakhtiniana, conforme explica o tradutor Paulo Bezerra (BAKHTIN, 1952-1953/2003), advêm do termo russo viskázivanie, significando tanto o ato de enunciar em palavras, como o seu resultado, um romance, por exemplo. Por isso, o tratamento dado ao enunciado equivale ao da enunciação.

5 Em 1929, Bakhtin publicou Problemas da obra de Dostoiévski. Somente em 1963, publicou a versão reformulada com o título definitivo: Problemas da poética de Dostoiévski (BEZERRA, 2015).

6 No Prefácio da obra Teoria do romance I: A estilística (BAKHTIN, 1930-1936/2015), Paulo Bezerra discute a tradução da palavra russa raznorétchie, traduzida no Brasil como "pluringuismo" ou "heteroglossia". Embora concorde que a palavra "pluringuismo" seja "mais palatável ao leitor brasileiro" do que "heteroglossia", observa que "difere semanticamente do original russo e do sentido que Bakhtin lhe atribui". Segundo o 
tradutor, a palavra russa é formada por ráznie (diversos) e riétchi (discursos, falas), o que significa "diversidade de discursos" ou "heterodiscurso", opção adotada na obra (BEZERRA, p. 11-12).

7 Blog do Editor: <http://wp.clicrbs.com. br/editor/2012/01/06/do-leitor-charge-de-iotti-foi-o-assunto-mais-comentado-pelos-leitores/?topo=13,1,1,,,13>.

8 O Grito do Bicho: <http://www.ogritodobicho. com/2012/01/charge-infeliz-sobre-abandono-de. html>.

9 No dia 14 de agosto de 2012, foi divulgado o Índice de Desenvolvimento da Educação Básica (IDEB) de 2011, que revelou a situação preocupante do Ensino Médio no Rio Grande do Sul. Enquanto em 2009 o indicador havia apresentado crescimento de 3,7 para 3,9 , o verificado em 2011 voltou para 3,7 - a meta era de 4,0 (ClicRBS).

10 Discussões iniciais sobre a leitura da charge foram apresentadas, em 2012, no VII Senale, Seminário Nacional de Linguagem e Ensino, na Universidade Católica de Pelotas, e, em 2013, no $2^{\circ}$. CIPLOM, Congresso Internacional de Profesores de Lenguas Oficiales del MERCOSUR, na Universidade de Buenos Aires.

11 Sobre discussões relativas a gêneros informativos e opinativos no campo jornalístico, consultar obras de José Marques de Melo, como Jornalismo opinativo: gêneros opinativos no jornalismo brasileiro (2003).

12 G1 - Globo.com: <http://g1.globo.com/rs/ rio-grande-do-sul/noticia/2011/12/campanha-contra-abandono-de-animais-nas-estradas-e-lancada-no-rs.html>.

13 A charge pode ser consultada no Blog do Editor: <http://wp.clicrbs.com.br/editor/2012/01/06/ do-leitor-charge-de-iotti-foi-o-assunto-mais-comentado-pelos-leitores/?topo=13,1,1,,,13>.

14 Há diferentes versões para o enunciado de Jesus, variando entre "Meu Deus, meu Deus, por que me abandonaste?" e "Deus meu, Deus meu, por que me desamparaste?".

\section{Referências}

AMORIM, M. Dialogisme et altérité dans les sciences humaines. Paris: Editions L’Harmattan, 1996.

O pesquisador e seu outro. Bakhtin nas ciências humanas. São Paulo: Musa, 2001.

. Raconter, démontrer,... survivre. Formes de savoirs et de discours dans la culture contemporaine. Paris: Édition Érès, 2007.
BAJTIN, M./VOLOCHINOV, V. La construcción de la enunciación (1929-1930). In: SILVESTRI, A.; BLANCK, G. Bajtin y Vigotski: La organización semiótica de la conciencia. Barcelona: Antrhopos, 1993. p. 245-277.

BAKHTIN, M. Os gêneros do discurso (19521953). In: Estética da criação verbal (1979). Trad. Maria Ermantina Galvão Gomes e Pereira. São Paulo: Martins Fontes, 1992. p. 277-326.

. Problemas da poética de Dostoiévski (1929/1963). 2. ed. Trad. Paulo Bezerra. Rio de Janeiro: Forense Universitária, 1997.

O problema do conteúdo, do material e da forma na criação literária (1924). In:__. Questões de literatura e de estética. A teoria do romance. Trad. Aurora Fornoni Bernadini et al. São Paulo: Unesp, 1998. p. 13-70.

$\mathrm{O}$ autor e a personagem na atividade estética (1922-1924). In: Estética da criação verbal (1979). 4.ed. Trad. Paulo Bezerra. São Paulo: Martins Fontes, 2003. p. 3-192.

Os gêneros do discurso (1952-1953). In: _. Estética da criação verbal (1979). 4.ed. Trad. Paulo Bezerra. São Paulo: Martins Fontes, 2003. p. 261-306.

O problema do texto na linguística, na filologia e em outras ciências humanas (1959-1961). In: . Estética da criação verbal (1979). 4.ed. Trad. Paulo Bezerra. São Paulo: Martins Fontes, 2003. p. 307-335.

Apontamentos de 1970-1971. In:__. Estética da criação verbal (1979). 4.ed. Trad. Paulo Bezerra. São Paulo: Martins Fontes, 2003. p. 367-392.

. Para uma filosofia do ato responsável (1920-1924). Trad. Valdemir Miotello e Carlos Alberto Faraco. São Carlos: Pedro \& João Editores, 2010.

Teoria do romance I: A estilística (1930-1936). Organização da edição russa de Serguei Botcharov e Vadim Kójinov. Tradução, prefácio, notas e glossário de Paulo Bezerra. São Paulo: Editora 34, 2015. 
BAKHTIN, M./VOLOCHINOV, V. N. Marxismo e filosofia da linguagem: problemas fundamentais do método sociológico na ciência da linguagem (1929). Trad. Michel Lahud e Yara Frateschi Vieira. 7. ed. São Paulo: Hucitec, 1995.

BEZERRA, P. Prefácio. In: BAKHTIN, M. Teoria do romance I: A estilística (19301936). Organização da edição russa de Serguei Botcharov e Vadim Kójinov. Tradução, prefácio, notas e glossário de Paulo Bezerra. São Paulo: Editora 34, 2015. p. 7-13.

[Blog do editor, Zero Hora]. Disponível em: <http://wp.clicrbs.com.br/editor/2012/01/06/ do-leitor-charge-de-iotti-foi-o-assunto-mais-comentado-pelos-leitores/?topo=13,1,1,,,13>. Acesso em: 12 ago. 2012.

CHARAUDEAU, P. Discurso das mídias. 2a. reimpressão. Trad. Angela M. S. Corrêa. São Paulo: Contrexto, 2009.

CLARK, K.; HOLQUIST, M. Mikhail Bakhtin (1984). Trad. J. Guinsburg. São Paulo: Perspectiva, 1998.

[CLIC RBS]. Disponível em: <http://zerohora. clicrbs.com.br/rs/geral/noticia/2012/08/indice-nacional-aponta-queda-na-qualidade-do-ensino-medio-gaucho-3853114.html\#miolo>. Acesso em: 15 ago. 2012.

DI FANTI, M. G. C. A constitutiva e tensa relação com o discurso do outro: questões de pesquisa e de formação na contemporaneidade. Projeto de pesquisa, PUCRS, 2014.

FARACO, C. A. Linguagem \& diálogo: as ideias linguísticas do Círculo de Bakhtin. São Paulo: Parábola Editorial, 2009.

[G1 - Globo.Com]. Disponível em: <http:// g1.globo.com/rs/rio-grande-do-sul/noticia/2011/12/campanha-contra-abandono-de-animais-nas-estradas-e-lancada-no-rs. html>. Acesso em 14 ago. 2012.

MARQUES DE MELO, J. Jornalismo opinativo: gêneros opinativos no jornalismo brasileiro. 3. ed. Campos do Jordão: Mantiqueira, 2003.
MORSON, G. S.; EMERSON, C. Mikhail Bakhtin: criação de uma prosaística. Trad. Antonio de Pádua Danesi. São Paulo: Editora da Universidade de São Paulo, 2008.

[O grito do bicho]. Disponível em: http:// www.ogritodobicho.com/2012/01/charge-infeliz-sobre-abandono-de.html. Acesso em 12.08.2012.

PONZIO, A. Problemas de sintaxe para uma linguística da escuta. In: BAKHTIN, M. Palavra própria e palavra outra na sintaxe da enunciação. Organização de Valdemir Miotello. Trad. Allan Tadeu Pugliese et al. São Carlos: Pedro \& João, 2011. p. 7-57.

SOBRAL, A. A estética em Bakhtin (Literatura, Poética e Estética). In: DE PAULA, L.; STAFUZZA, G. Círculo de Bakhtin: teoria inclassificável. São Paulo: Mercado de Letras, 2010. p. 53-88.

VOLOSHINOV, V./BAKHTIN, M. M. A palavra na vida e na poesia. Introdução ao problema da poética sociológica (1926). In: BAKHTIN, M. Palavra própria e palavra outra na sintaxe da enunciação. Organização de Valdemir Miotello. Trad. Allan Tadeu Pugliese et al. São Carlos: Pedro \& João, 2011. p. $145-181$.

VOLOŠINOV, V. N. Marxisme et philosophie du langage: les problèmes fondamentaux de la méthode sociologique dans la science du langage (1929). Nouvelle édition bilingue traduite du russe pas Patrick Sériot et Inna Tylkowski-Ageeva. Limoges: Lambert-Lucas, 2010. 